Abstracta Iranica Iranica

Revue bibliographique pour le domaine irano-aryen

Volume 32-33 | 2013

Comptes rendus des publications de 2009-2010

\title{
Maria Francesca Bonetti, Alberto Prandi (éds.). La Persia Qajar. Fotografi italiani in Iran 1848-1864
}

\section{Rédaction}

\section{(2) OpenEdition}

12 Journals

\section{Édition électronique}

URL : http://journals.openedition.org/abstractairanica/40649

DOI : 10.4000/abstractairanica.40649

ISSN : 1961-960X

Éditeur :

CNRS (UMR 7528 Mondes iraniens et indiens), Éditions de l'IFRI

\section{Édition imprimée}

Date de publication : 1 décembre 2013

ISSN : 0240-8910

\section{Référence électronique}

Rédaction, « Maria Francesca Bonetti, Alberto Prandi (éds.). La Persia Qajar. Fotografi italiani in Iran 1848-1864 », Abstracta Iranica [En ligne], Volume 32-33 | 2013, document 235, mis en ligne le 01 juillet 2016, consulté le 03 octobre 2020. URL : http://journals.openedition.org/abstractairanica/40649 ; DOI : https://doi.org/10.4000/abstractairanica.40649

Ce document a été généré automatiquement le 3 octobre 2020.

Tous droits réservés 


\title{
Maria Francesca Bonetti, Alberto Prandi (éds.). La Persia Qajar. Fotografi italiani in Iran 1848-1864
}

\author{
Rédaction
}

\section{RÉFÉRENCE}

Maria Francesca Bonetti, Alberto Prandi (éds.). La Persia Qajar. Fotografi italiani in Iran 1848-1864. Roma, Istituto Nazionale per la Grafica, Peliti Associati, 2010, 245 (+1) p., 11 figs., 120 planches, 282 photographies cataloguées, bibliographie.

1 «La Perse Qajar: Photographes italiens en Iran (1848-1864)», c'est le beau catalogue d'une Exposition sans précédents, laquelle a eu lieu dans le palais de l'Institut National pour la Graphique (Rome, 11 février-5 avril 2010; ensuite à Modène, Fotomuseo Giuseppe Panini, 27 novembre 2010-13 mars 2011). Deux historiens de la photographie, M. F. Bonetti, spécialiste de cet Institut, et A. Prandi, professeur à l'Université de Venise, ont réalisé l'exposition et le catalogue, fruits de leurs recherches à travers des archives, des bibliothèques et des musées de plusieurs pays (voir à la dernière page, non numérotée, la liste des collections qui ont octroyés le copyright en Florence, Turin, Venise, Paris, Rome, Bâle et Oxford).

2 A. M. Piemontese, "Apporti tecnici d'italiani in Persia nel XIX secolo », p. 13-21, expose l'histoire des militaires, médecins et divers civils italiens qui pendant le $\mathrm{XIX}^{\mathrm{e}} \mathrm{s}$. ont émigré en Iran, y apportant la connassaince ou la pratique moderne de quelques éléménts techniques, dont la photographie par Luigi Pesce, colonel napolitain au service de l'Armée Royale Qājār. M. F. Bonetti, «Gli esordi della fotografia in Persia: contributi italiani», p. 23-32, présente en particulier les contributions de Pesce, du général Antonio Giannuzzi et de Luigi Montabone. Ce dernier est le photographe turinois qui prépara l'Album photographique de l'Ambassade Extraordinaire du Royaume d'Italie en Iran (1862): une série d'images historiques qui ont embelli le 
catalogue et l'espace centrale de l'exposition elle-même. A. Prandi, «1862 », p. 29-32, Claudio Zanier, "Carlo Orio et la questione "seta" nella Missione Cerruti in Persia ", p. 33-36, et Roberto Poggi, «Le raccolte naturalistiche di Giacomo Doria in Persia (1862-1863)», p. 37-38, examinent les données diplomatiques et scientifiques de l'Ambassade. A. Prandi, «Letteratura occidentale di storia della fotografia d'epoca Qajar. Saggio bibliografico », p. 39-48, offre un substantiel essai bibliographique sur la littérature occidentale de la photographie d'époque Qājār. L'exposition et le catalogue considèrent aussi les photographes Frances Carlhian, Henri de Couliboeuf de Bocqueville et Marcel Gustave Laverdet.

\section{AUTEURS}

\section{RÉDACTION}

Directeur de la revue et secrétariat (Paris) 